\title{
VICTIMS OF TERRORISM-RELATED DISASTERS: EXPERIENCE OF A HOSPITAL ON THE BORDER OF IRAQ
}

\author{
Yunus Emre Ozluer', Sinem Dogruyol ${ }^{2}$, KIvanç Karaman ${ }^{3}$, Talha Dogruyol ${ }^{4}$ \\ 'Department of Emergency Medicine, Faculty of Medicine, Adnan Menderes University, Aydin, Turkey \\ ${ }^{2}$ Department of Emergency Medicine, Manisa Merkezefendi State Hospital, Manisa, Turkey \\ ${ }^{3}$ Department of Emergency Medicine, Faculty of Medicine, Süleyman Demirel University, Isparta, Turkey \\ ${ }^{4}$ Department of Thoracic Surgery, Manisa City Hospital, Manisa, Turkey
}

\begin{abstract}
INTRODUCTION: We aimed to analyze the data of patients who were admitted to our emergency department (ED) because of terrorism-related injuries.
\end{abstract}

MATERIAL AND METHODS: We have retrospectively analyzed the patients who were admitted to a state hospital's ED with terrorism-related injuries between 01.01.2016 and 01.01.2018. The data about mechanism of injury, injured body part, Abbreviated Injury Scale scores, management, and outcomes: discharge from the ED, hospitalization to the ward, transfer to the operation room and/or intensive care unit, transfer to a tertiary hospital, the length of stay in the hospital, exitus, and re-admission were analyzed.

RESULTS: Of the 296 patients admitted, $93.9 \%$ were male and $6.1 \%$ were female, and $14.2 \%$ of the cases were children. Gunshot wounds represented $66.2 \%$ of the cases, whereas $33.8 \%$ of them had explosion injuries. Overall ED mortality rate was $15.5 \%$. The mortality rate was higher in gunshot wounds. The most affected regions were the extremities, pelvis and external organs. Thorax injuries had the highest rate of mortality. Of the patients, $42.2 \%$ were discharged from the ED. The highest rate of ED discharge was with extremities, pelvis and external organ injuries. The ED mortality rate in the pediatric group was $21.4 \%$. Gunshot wounded group had a higher mortality rate. Similar to adults the highest mortality rate was in the thoracic injury group.

CONCLUSIONS: Because of the variety of injuries, the management of terrorism victims requires a broad perspective. We think that the ED mortality rate can be used to assess the quality of the critical care provided.

KEY WORDS: emergency department, mortality, pediatric, terrorism

Disaster Emerg Med J 2021; 6(1): 26-32

\section{INTRODUCTION}

Terrorism is the physical and psychological act of violence that targets military personnel and innocent civilians; the goal is to cause dismay, consternation, murder, and mayhem for political or religious motivations $[1,2]$. Turkey is the 14 th most affected country in the world when it comes to the effects of terrorism; the country has experienced more than
5.000 deaths from terrorism between 1970 and $2013[3,4]$.Terrorist attacks in the city centers mostly target civilians and mainly caused by firearm injuries, roadside bombs, and suicide bombers. In rural areas, these terrorist attacks are mostly war-like attacks against soldiers. However, the situation in our country differs. In these attacks, both military personnel in city centers and civilian people in rural areas can 
be targeted simultaneously. This variability in terrorism-related attacks has also changed the affected population over time. The population that is being affected by terrorism has changed over the years to include women and children, who are now the subjects of gunshot wounds (GSW) and explosions as well as men.

The injury mechanism is known to be a major defining factor of the clinical effects of the injury itself $[5,6]$. For example, handmade explosives (HE) are widely used in terrorist attacks because of their low cost, but they cause more deaths and amputations than GSW because they can be enhanced with nails and metallic marbles [7]. Therefore, managing terrorism-related injuries must be given extra attention because of the broad-spectrum terrorism-related injuries fall under, including GSW, various types of explosion injuries, and even burns [8].

As the danger of mass casualties from terrorist attacks has increased worldwide, quality medical care has become an increasing concern $[9,10]$. Considering that the first encounters with the victims of terrorism happen in emergency departments (ED), the analysis of previous cases and their patient populations, types, mechanisms of the injuries, and management strategies may help ED physicians make better decisions regarding differentiating critically ill patients, making rough risk stratifications, and transferring these patients to proper health facilities. Based on this, we aimed to analyze the data of patients who were admitted to our ED because of terrorism-related injuries.

\section{MATERIAL AND METHODS}

We have retrospectively analyzed 296 patients who were admitted to a state hospital's ED with terrorism-related GSW and HE injuries between 01.01.2016 and 01.01.2018. The hospital where the study was conducted is in a city Hakkari, on the border between Iraq and Turkey. During this period, both military personnel and civilian people were evaluated in the same emergency room.

The analysis included age variation, gender, mechanism of injury, injury site, abbreviated injury scale (AIS) 2005 scores, interventions, ED management, and outcomes which are: discharge from ED, hospitalization to the ward, transfer to operation room (OR) and/or intensive care unit (ICU), transfer to a tertiary hospital, length of stay in the hospital, exitus, and re-admission. The ED mortality rate has been specifically calculated in this study. The mechanisms of injury were considered in two categories: GSW and HE injuries. The frequency of organ injury was examined in the aspect of the criticality of the injury that mandated urgent intervention, the most affected system, and the injury that causes a life-threatening situation that led to causality.

These anatomic body regions affected by trauma were classified in a way similar to the calculation in AIS: head and neck; face; thorax; abdomen; extremities, pelvis and external organs.

The relation of the morbidity and mortality to these anatomic regions, in addition to interventions and management strategies (transfer to the ward, $\mathrm{OR}$ and/or ICU and discharge from ED), were investigated. In the first step, all data were analyzed before patients were divided into age groups. Patients between 0 and 18 years old were analyzed distinctly as a pediatric subgroup. In the second step, this pediatric group was examined separately. Also, it was examined whether the results of this pediatric group reflect the whole patient group.

Statistical analyses were made using IBM Statistical Package for Social Sciences (SPSS) for Windows, Version 20.0 (IBM Corp. Armonk, NY: USA. Released 2011). Definitive statistics and a standard deviation were calculated for the age variable, which was considered a continuous variable. Categorical variables were statistically analyzed with a chi-square test. Mann-Whitney $U$ and One-Way ANOVA tests were used to compare independent groups. Logistic regression analysis was performed to examine the variables affecting mortality and hospitalization outcomes.

\section{RESULTS}

Of the 296 patients enrolled in the study, 93.9\% $(n=278)$ were male and $6.1 \%(n=18)$ were female. $61.5 \%(n=182)$ of all patients were soldiers. The pediatric group represented 14.2\% ( $n=42,33$ male, 9 female) of the cases. The mean age of all civil patients was $25.9 \pm 10.5$ and the mean age of soldiers was $26.8 \pm 6.9$ (Figure 1).

According to the mechanism of injury, $66.2 \%$ ( $n=196)$ of the cases suffered GSW, whereas 33.8\% $(n=100)$ of the cases were subjects of explosion injuries. In the soldier subgroup, the injury mechanism was distributed as 79.7\% ( $n=145)$ GSW and $20.3 \%(n=37)$ HE. The frequency of GSW injuries was higher in the soldier subgroup. This difference 


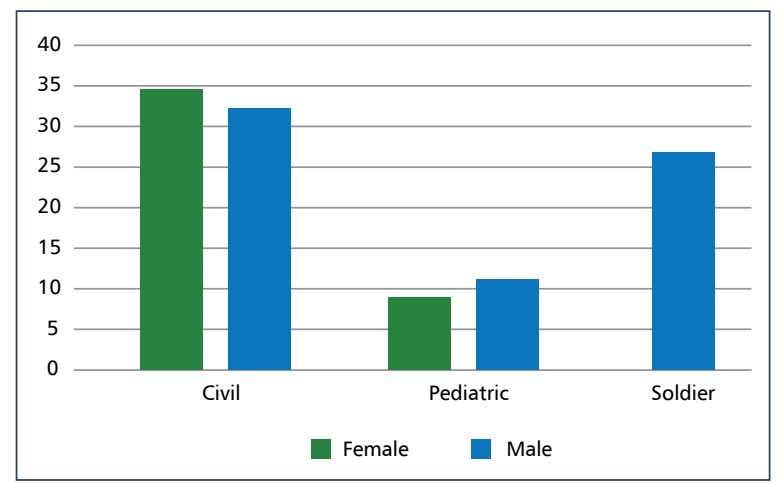

FIGURE 1. Distribution of patient groups by age and gender

was statistically significant $(p=0.000)$. There was no difference between children and civilian adults in terms of injury mechanisms.

The most affected anatomic regions in the overall patient population were the extremities, pelvis and external organs $(p<0.001)$ (Table 1). These rates were similar for civil and military personnel. In the pediatric subgroup, this ratio was the same, extremities, pelvis and external organs were the most affected body parts with a ratio of $57.1 \%(n=24)$. This was followed by head and neck injuries $(n=8)$, thorax injuries $(n=6)$, abdominal injuries $(n=2)$ and face injuries $(n=2)$ with the ratio of $19 \%$, $14.3 \%, 4.8 \%$, and $4.8 \%$, respectively.

When the mechanism of injury and the anatomical body regions were examined, a statistically significant relationship was found between them $(p<0.001)$. The injuries associated with GSW were observed in $81.4 \%$ of the head and neck, $80.6 \%$ in the chest and $81.2 \%$ in the abdomen. However, $66.7 \%$ of facial injuries were due to HE (Table 1). The distribution of these injuries in the military subgroup was; $88.9 \%$ head and neck, $90.5 \%$ chest and $100 \%$ abdomen $(p=0.006)$. Also, we found a statistically significant relationship in the pediatric group ( $p=0.003$ ). We found that $87.5 \%$ of head and neck injuries were related to GSW. And all of the facial injuries and $79.2 \%$ of the extremities, pelvis and external organ injuries were associated with HE.

The mean AIS score of all patients was $2.73 \pm 1.50$. AlS scores according to the affected anatomical regions were shown in Table 2 . The mean AIS scores in head and neck, thorax and abdomen injuries were statistically higher than face and extremities, pelvis and external organs injuries $(p<0.001)$. A statistically significant relationship was found between the AIS score and mortality for

\begin{tabular}{|c|c|c|c|c|c|}
\hline & \multicolumn{5}{|c|}{ Injury mechanism } \\
\hline & \multicolumn{2}{|c|}{ HE } & \multicolumn{2}{|c|}{ GSW } & \multirow{2}{*}{$\frac{\text { Total }}{\mathrm{n}}$} \\
\hline & $\mathrm{n}$ & $\%$ & $\mathrm{n}$ & $\%$ & \\
\hline \multicolumn{6}{|l|}{ Body region } \\
\hline Head and neck & 11 & 18.6 & 48 & 81.4 & 59 \\
\hline Face & 20 & 66.7 & 10 & 33.3 & 30 \\
\hline Thorax & 6 & 19.4 & 25 & 80.6 & 31 \\
\hline Abdomen & 3 & 18.8 & 13 & 81.2 & 16 \\
\hline Extremities, pelvis, external organs & 60 & 37.5 & 100 & 62.5 & 160 \\
\hline
\end{tabular}

GSW - Gunshot Wounds; HE — Handmade Explosives; $n$ - number

Table 2. Abbreviated injury scale scores of patients according to the affected anatomical regions

\begin{tabular}{|l|l|c|c|c|}
\hline \multicolumn{1}{|c|}{ Anatomic region } & $\mathrm{n}$ & Mean & SD \\
\hline \multirow{4}{*}{ AIS } & Head and neck & 59 & 3.4 & 1.79 \\
\cline { 2 - 5 } & Face & 30 & 1.6 & 0.81 \\
\cline { 2 - 5 } & Thorax & 31 & 4.4 & 1.63 \\
\cline { 2 - 5 } & Abdomen & 16 & 3.9 & 0.99 \\
\cline { 2 - 5 } & Extremities, pelvis and external organs & 160 & 2.2 & 0.96 \\
\hline
\end{tabular}

AIS — Abbreviated Injury Scale; $\mathrm{n}$ - number; SD — Standard Deviation 


\begin{tabular}{|c|c|c|c|}
\hline & \multicolumn{3}{|c|}{ Pediatric age groups } \\
\hline & $\begin{array}{c}0-5 \text { years } \\
n=6\end{array}$ & $\begin{array}{c}6-10 \text { years } \\
n=13\end{array}$ & $\begin{array}{c}11-17 \text { years } \\
n=23\end{array}$ \\
\hline \multicolumn{4}{|l|}{ Outcomes } \\
\hline ED discharge & $66.7 \%$ & $61.5 \%$ & $34.8 \%$ \\
\hline Transfer to ward & - & $15.4 \%$ & $21.7 \%$ \\
\hline OR and/or ICU & $16.7 \%$ & $15.4 \%$ & $4.3 \%$ \\
\hline Tertiary center transport & - & $7.7 \%$ & $4.3 \%$ \\
\hline Exitus & $16.7 \%$ & - & $21.4 \%$ \\
\hline \multicolumn{4}{|l|}{ Length of hospital stay } \\
\hline Mean, day & 6 & 10.8 & 11.6 \\
\hline
\end{tabular}

ED — Emergency Department; GSW — Gunshot Wounds; HE — Handmade Explosives; ICU — Intensive Care Unit; $\mathrm{n}$ - number; OR — Operation Room

all patients (mean difference $3.37 ; 95 \% \mathrm{Cl}=3.16-$ $-3.581)(p=0.000)$. Also, there was a statistically significant relationship between the AIS score and mortality in the pediatric group (mean difference $3.27,95 \% \mathrm{Cl}=2.76-3.78)(\mathrm{p}=0.000)$.

We analyzed that $42.2 \%(n=125)$ of the patients were discharged from the ED, $17.5 \%(n=52)$ were hospitalized in various wards, $16.8 \%$ of them $(\mathrm{n}=50)$ were transferred to the ICU and/or OR, and $7.8 \%(n=23)$ of the patients were transported to a tertiary center. The mean length of hospital stay for all patients was 12.1 (1-86 days). No significant difference was found between the patient groups in terms of hospital stay $(p>0.05)$. The length of hospital stay was similar in patients with GSW (52\% hospitalized for longer than 7 days) and with HE (55\% hospitalized for longer than 7 days).

In the pediatric group, $47.6 \%(n=20)$ of the patients were discharged from the ED, $16.7 \%$ of them were hospitalized in the ward, 9.5\% $(n=4)$ were transferred to the ICU and/or OR, and $4.8 \%$ $(n=2)$ of the children were transferred to a tertiary center. The mean length of hospital stay for pediatric patients was 10.3 (1-28 days). Overall pediatric ED mortality was $21.4 \%(n=9)$. Mortality and length of hospital stay did not vary significantly between age groups of pediatric group (Table 3 ).

Overall ED mortality was $15.5 \%(n=46)$. Forty patients $(87.0 \%)$ were injured by GSW whereas 6 patients $(13.0 \%)$ were injured by HE $(p=0.001)$. We have seen that $34.4 \%(n=43)$ of patients with HE injuries were discharged from the ED. This ratio was $65.6 \%(n=82)$ in patients with GSW $(p<0.001)$ (Figure 2). In the pediatric group, the ED

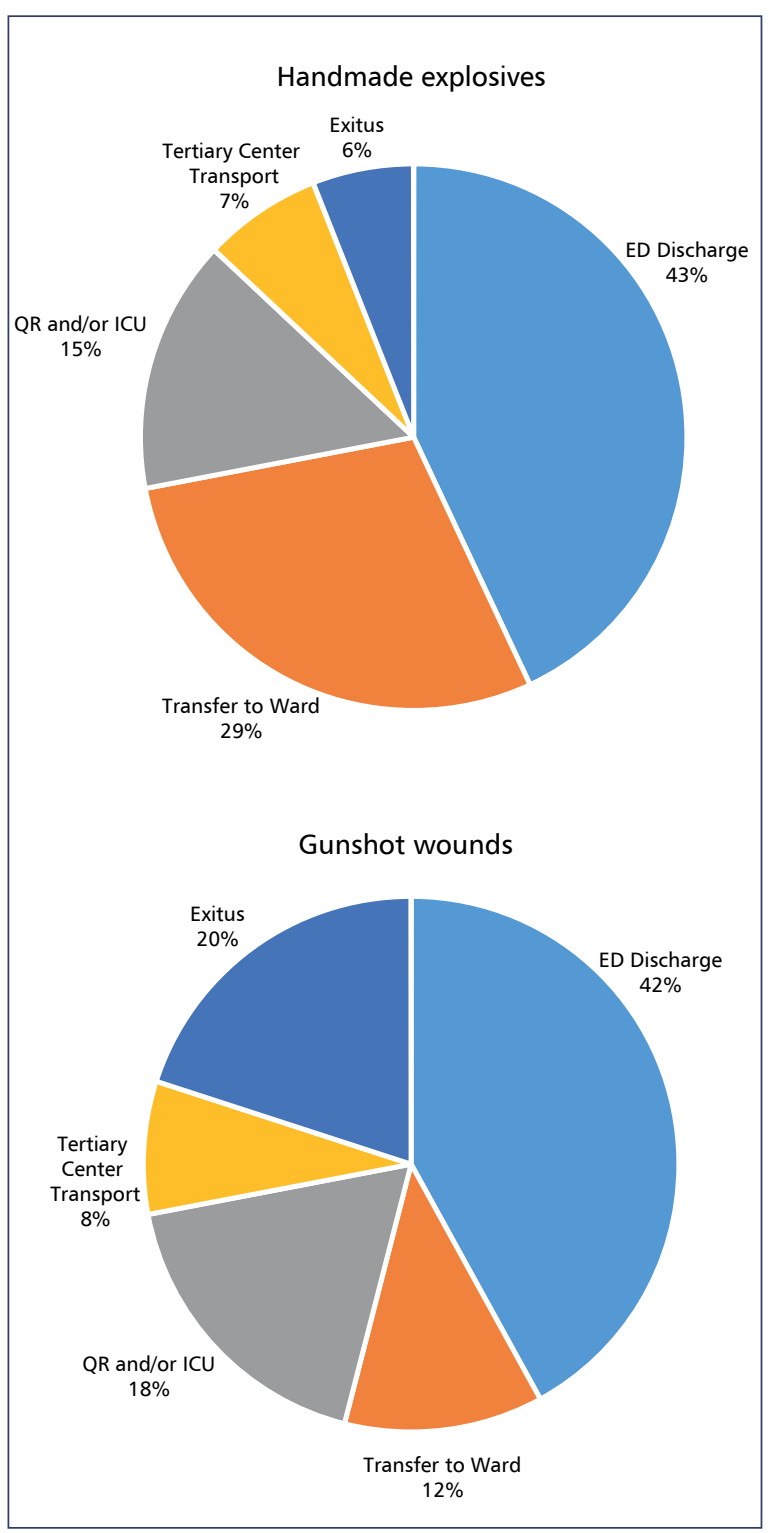

FIGURE 2. The relationship between the injury mechanism and the patient outcomes 
mortality rate was $88.9 \%(n=8)$ and $11.1 \%(n=1)$ for GSW and $H E$, respectively. For patients suffered from $H E, 85.0 \%(n=17)$ were discharged from the $\operatorname{ED}(p=0.003)$.

Looking at the relationship between the injured anatomic regions and the patient outcome for all patients the highest ED mortality rate was associated with injuries to the thorax $(p<0.001)$. Of the 31 patients who suffered thorax injuries, 20 (64.5\%) died. This was followed by head and neck injuries with a ratio of $33.9 \%$. The highest rate of urgent surgical interventions and subsequent ICU admissions was in patients with abdominal injuries, at a rate of $81.2 \%$ (13 out of 16 patients); the highest rate of ED discharge was in patients with extremities, pelvis and external organs injuries. Eighty-five of the $125(68 \%)$ patients who were discharged from the ED were in this group. In the pediatric group, all patients with abdominal injuries had urgent surgical interventions. The highest ED mortality rate was in the thorax injury group (66.7\%); in this injury group, 4 out of the 6 patients died. This was followed by patients with head injuries at $62.5 \%$ (5 out of the 8 patients). Also, there was a significant relationship between the injury site and outcomes in this group. When the pediatric group was excluded, the statistical results were similar in terms of injured anatomic regions and patient outcomes for the 254 patient group $(p<0.001)$.

Sixteen patients $(5.4 \%)$ were re-admitted to the $E D$, and 32 patients (10.8\%) visited various outpatient clinics within 30 days after initial admission. The re-admission rate was significantly higher in patients with GSW than with HE: $20.9 \%$ and $7 \%$, respectively $(p=0.006)$.

Logistic regression models were used to examine the effect of age, gender, patient subgroup, injury mechanism, injured anatomic region, AIS and patient outcome factors on patient mortality and hospitalization. It was observed that these parameters had no significant effect on mortality. However, we found that three variables (soldier subgroup, trauma mechanism, and AIS) were effective in hospitalization. Being military personnel increased the probability of hospitalization (OR $0.30,95 \% \mathrm{Cl}$ 0.15-0.62). Injury mechanism, i.e., $\mathrm{HE}$, (OR 0.25 , $95 \% \mathrm{Cl} 0.13-0.49)$ and high AIS (OR 1.59, 95\% Cl $1.18-2.13)$ also increased the probability of hospitalization.

\section{DISCUSSION}

Terrorism-related activities are spreading throughout the world. Over the past few decades, there has been a significant increase in global terrorism incidents [11]. In correlation with this increase, civilian casualties are also rising [12]. As per the literature that indicates that terrorism mostly affects young men, the vast majority of our patients were young men. The main reason for this could be that the security forces in the war zones are mostly men. Besides, these security forces are the first to respond to terrorist attacks that targeting civilians [13]. However, even when the soldiers were excluded from the analysis, we observed that male domination continued in accordance with the literature [14].

In the literature, pediatric trauma mortality rates in civilian-targeted terrorist attacks were found to be higher than for any other kind of pediatric traumatic injuries [15]. Children were twice as likely as adults (or adolescents) to present with severe injuries in terrorism-related activities [16]. In our study, 14.2\% of the patient population was under the age of 18. In accordance with the literature, we found high mortality rates in the pediatric population above 10 years of age. Unfortunately, the total pediatric mortality rate in our study was two times higher than in the literature.

Peleg et al. reported that GSW usually presents with moderate-level injuries, whereas explosion injuries are more associated with a high rate of mortality [17]. The authors also stated that both types of injuries have similar in-hospital mortality rates, but the length of stay in the ICU for explosion victims was longer than GSW victims. Unlike Peleg et al., we noticed that most of the victims who died were associated with GSW, and explosion victims were frequently hospitalized in the ward. Similar to the adult group, GSW victims had a higher rate of mortality in the pediatric group, whereas most of the patients with explosion injuries were discharged from the ED.

In our study, the victim's extremities, pelvis and external organs were the most affected anatomic regions, which is in line with the literature [18, 19]. This was followed by head and neck, thorax, face, and abdominal injuries. In contrast with other injured regions, most of the patients with extremities, pelvis and external organ injuries were safely discharged from the ED. We acknowledged that the highest mortality rate was associated with tho- 
rax and head and neck injuries [20]. This is logical, considering that this region holds the heart, lungs, and other major vessels. Although, in a study where Amir et al. examined pediatric terrorism victims in Israel, the authors reported the highest mortality rate was associated with traumatic brain injuries; in our study, the highest mortality rate was linked to thorax injuries, which was similar to the adult group [15]. We assume that the mechanism of injury plays a definitive role in reaching the rate of mortality in the pediatric group. Most of the pediatric patients are injured while playing with a bomb setup or unexploded automatic rifle ammunition. Thus, these types of injuries mostly happened close to the victims' bodies.

Trauma scoring systems are systems that can help predict trauma severity. Abbreviated Injury Scale, which was used in this study, was an anatomic scoring system and we found that high scores were associated with high mortality [21].

The ED mortality rate was $87 \%$ for GSW and $13 \%$ for HE in our study. This may be because of the bimodal distribution of the blast injuries. According to the data obtained, if a victim survives an explosion, he or she is quite likely to be discharged from the ED and with a lower rate of ED mortality. In addition, the fact that Emergency Health Services frequently use the scoop and run technique in the explosion area may reduce the transport time and have an impact on mortality rates [22]. Another factor might be the evolved skills and experience of the ED personnel in years in managing this unique type of patient and coherent and exemplary collaboration with the emergency physicians, surgeons, cardiothoracic surgeons, orthopedists, and neurosurgeons as a trauma team in the ED.

We observed that re-admissions to the hospital were mostly in outpatient clinics. Avitzour et al. found that the mechanism of injury did not affect re-admission rates [23]. For the current study, readmission rates in patients with GSW were significantly higher than explosion victims. Thus, we may assume that the duration of recovery for GSW is longer than explosion injuries, and GSW are associated with far more degradation of the victim's quality of life. This situation creates an excessive cost burden and workforce loss to the economy when considered countrywide.

For the current study, there are various limitations. First, this was a retrospective cohort study. Second, we could only scan computer logs and tomography images. Thus, we could not obtain information about vital signs and important determinants, such as the Glasgow Coma Scale and Prehospital Revised Trauma Score.

We assumed that our sample size of 296 patients would be enough to achieve an appropriate statistical significance level when compared with similar reports in the literature [24]. For this study, we would like to highlight our concept of ED mortality. We defined this as the mortality rate in the period of the patient from the beginning of the admission to ED (door), primary and secondary evaluations, laboratory and screening studies, as needed, to the outcome (OR, ICU, in the ward, discharge, or exitus). We think that the ED mortality rate in terrorism-related patients may reflect the effectiveness and the ability of emergency departments in the well-directed management of these patients. We also believe that this may reflect the quality of critical health care in the ED.

Another prominent feature of our study was the analysis of the pediatric group, especially considering the rarity of the reports regarding pediatric terrorism-related injuries in the literature. We also could not find a report investigating the relationship between the mechanism of injury and the rate of hospital readmissions.

\section{CONCLUSIONS}

The ED management of terrorism-related injuries can be challenging because it requires a broad perspective. We think that the ED mortality rate in victims of terrorism may be a useful indicator when assessing the functionality and the skill of reacting to disarray in the emergency departments. It can also reflect the quality of the critical care provided in the ED.

Conflicts of interest: The authors declare no conflicts of interest regarding the publication of this paper.

\section{REFERENCES}

1. Nanninga P. Islam and Suicide Attacks. 2019, doi: 10.1017/9781108670524.

2. Evrin T, Demirel B, Yilmaz B, et al. Post-traumatic stress disorder after terrorist attack in healthcare professionals. Disaster and Emergency Medicine Journal. 2017; 2(1): 11-18, doi: 10.5603/demj.2017.0003.

3. Index. Global Alert. 2015, doi: 10.7312/gano17212-015. 
4. Strang K, Alamieyeseigha S. What and Where are the Risks of International Terrorist Attacks. International Journal of Risk and Contingency Management. 2015; 4(1): 1-20, doi: 10.4018/ijrcm.2015010101.

5. Haider AH, Chang DC, Haut ER, et al. Mechanism of injury predicts patient mortality and impairment after blunt trauma. J Surg Res. 2009; 153(1): 138-142, doi: 10.1016/j.jss.2008.04.011, indexed in Pubmed: 18805554.

6. Madsen AS, Laing GL, Bruce JL, et al. A comparative audit of gunshot wounds and stab wounds to the neck in a South African metropolitan trauma service. Ann R Coll Surg Engl. 2016; 98(7): 488-495, doi: 10.1308/rcsann.2016.0181, indexed in Pubmed: 27269237.

7. Covey $D C$. Blast and fragment injuries of the musculoskeletal system. J Bone Joint Surg Am. 2002; 84(7): 1221-1234, doi: 10.2106/00004623200207000-00022, indexed in Pubmed: 12107327.

8. Hanoch J, Feigin E, Pikarsky A, et al. Stab wounds associated with terrorist activities in Israel. JAMA. 1996; 276(5): 388-390, indexed in Pubmed: 8683817.

9. Rivkind Al, Blum R, Gershenstein I, et al. Trauma care and case fatality during a period of frequent, violent terror attacks and thereafter. World J Surg. 2012; 36(9): 2108-2118, doi: 10.1007/s00268-012-1637-6, indexed in Pubmed: 22588239.

10. Mikton CR, Butchart $A$, Dahlberg $L L$, et al. The world report on violence and health. Lancet. 2002; 360(9339): 1083-1088, doi: 10.1016/ S0140-6736(02)11133-0, indexed in Pubmed: 12384003.

11. Global Terrorism Index 2014. Human Rights Documents Online. , doi: 10.1163/2210-7975_hrd-1265-2015004.

12. START: National Consortium for the Study of Terrorism and Responses to Terrorism. Choice Reviews Online. 2014; 51(12): 51-6530-51-6530, doi: 10.5860/choice.51-6530.

13. Peleg K, Aharonson-Daniel L, Michael M, et al. Israel Trauma Group. Patterns of injury in hospitalized terrorist victims. Am J Emerg Med. 2003; 21(4): 258-262, doi: 10.1016/s0735-6757(03)00043-3, indexed in Pubmed: 12898479.

14. Sambasivan CN, Underwood SJ, Cho SD, et al. Comparison of abdominal damage control surgery in combat versus civilian trauma. J Trauma. 2010; 69 Suppl 1: S168-S174, doi: 10.1097/TA.0b013e3181e45cef, indexed in Pubmed: 20622613.
15. Amir LD, Aharonson-Daniel L, Peleg K, et al. Israel Trauma Group. The severity of injury in children resulting from acts against civilian populations. Ann Surg. 2005; 241(4): 666-670, doi: 10.1097/01. sla.0000157233.18787.cd, indexed in Pubmed: 15798470.

16. Jaffe DH, Peleg K. Israel Trauma Group. Terror explosive injuries: a comparison of children, adolescents, and adults. Ann Surg. 2010; 251(1): 138-143, doi: 10.1097/SLA.0b013e3181b5d7ab, indexed in Pubmed: 19838104.

17. Peleg K, Aharonson-Daniel L, Stein M, et al. Israeli Trauma Group (ITG). Gunshot and explosion injuries: characteristics, outcomes, and implications for care of terror-related injuries in Israel. Ann Surg. 2004; 239(3): 311-318, doi: 10.1097/01.sla.0000114012.84732. be, indexed in Pubmed: 15075646.

18. Mushtaque $M$, Mir MF, Bhat $M$, et al. Pellet gunfire injuries among agitated mobs in Kashmir. Ulus Travma Acil Cerrahi Derg. 2012; 18(3): 255-259, doi: 10.5505/tjtes.2012.47639, indexed in Pubmed: 22864719 .

19. Hebrang A, Henigsberg N, Golem AZ, et al. [Care of military and civilian casualties during the war in Croatia]. Acta Med Croatica. 2006; 60(4): 301-307, indexed in Pubmed: 17048781.

20. Bala M, Shussman N, Rivkind Al, et al. The pattern of thoracic trauma after suicide terrorist bombing attacks. J Trauma. 2010; 69(5): 1022-8; discussion 1028, doi: 10.1097/TA.0b013e3181f35c71, indexed in Pubmed: 21068606.

21. Gennarelli TA, Wodzin E. AIS 2005: a contemporary injury scale. Injury. 2006; 37(12): 1083-1091, doi: 10.1016/j.injury.2006.07.009, indexed in Pubmed: 17092503.

22. Cornwell EE. Current concepts of gunshot wound treatment: a trauma surgeon's perspective. Clin Orthop Relat Res. 2003(408): 58-64, doi: 10.1097/00003086-200303000-00006, indexed in Pubmed: 12616040

23. Avitzour $M$, Mintz $Y$, Liebergall $M$, et al. The burden of terrorism: high rate of recurrent hospital referrals. Injury. 2008; 39(1): 77-82, doi: 10.1016/j.injury.2007.08.035, indexed in Pubmed: 18164299.

24. AkkucukS, Aydogan A, Yetim I, et al. Surgical outcomes of a civil war in a neighbouring country. J R Army Med Corps. 2016; 162(4): 256-260, doi: 10.1136/jramc-2015-000411, indexed in Pubmed: 26055069. 